\title{
Current Strategies to Combat Cisplatin-Induced Ototoxicity
}

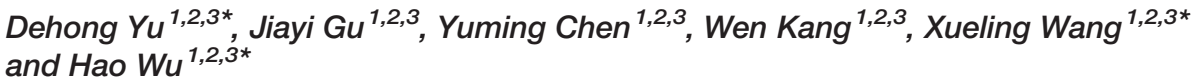 \\ 1 Department of Otolaryngology-Head and Neck Surgery, Shanghai Ninth People's Hospital, School of Medicine, Shanghai \\ Jiao Tong University, Shanghai, China, ${ }^{2}$ Ear Institute, School of Medicine, Shanghai Jiao Tong University, Shanghai, China, \\ ${ }^{3}$ Shanghai Key Laboratory of Translational Medicine on Ear and Nose Diseases (14DZ2260300), Shanghai, China
}

OPEN ACCESS

Edited by:

Salvatore Salomone,

University of Catania, Italy

Reviewed by:

Tejbeer Kaur,

Creighton University, United States

Sandeep Sheth

Larkin University, United States Katharine Fernandez,

National Institute on Deafness and

Other Communication Disorders

(NIDCD), United States

*Correspondence:

Dehong Yu

dehongyu@126.com

Xueling Wang

xuelingwang2013@163.com

Hao Wu

haowu@sh-jei.org

Specialty section: This article was submitted to Experimental Pharmacology and Drug Discovery,

a section of the journal

Frontiers in Pharmacology

Received: 20 April 2020 Accepted: 22 June 2020

Published: 03 July 2020

Citation:

Yu D, Gu J, Chen Y, Kang W, Wang $X$ and Wu H (2020) Current Strategies to Combat CisplatinInduced Ototoxicity.

Front. Pharmacol. 11:999. doi: 10.3389/fphar.2020.00999
Cisplatin is widely used for the treatment of a number of solid malignant tumors. However, ototoxicity induced by cisplatin is an obstacle to effective treatment of tumors. The basis for this toxicity has not been fully elucidated. It is generally accepted that hearing loss is due to excessive production of reactive oxygen species by cells of the cochlea. In addition, recent data suggest that inflammation may trigger inner ear cell death through endoplasmic reticulum stress, autophagy, and necroptosis, which induce apoptosis. Strategies have been extensively explored by which to prevent, alleviate, and treat cisplatin-induced ototoxicity, which minimize interference with antitumor activity. Of these strategies, none have been approved by the Federal Drug Administration, although several preclinical studies have been promising. This review highlights recent strategies that reduce cisplatin-induced ototoxicity. The focus of this review is to identify candidate agents as novel molecular targets, drug administration routes, delivery systems, and dosage schedules. Animal models of cisplatin ototoxicity are described that have been used to evaluate drug efficacy and side effect prevention. Finally, clinical reports of otoprotection in patients treated with cisplatin are highlighted. For the future, high-quality studies are required to provide reliable data regarding the safety and effectiveness of pharmacological interventions that reduce cisplatin-induced ototoxicity.

Keywords: cisplatin-induced ototoxicity, drug delivery systems, animal models, clinical trials

\section{HIGHLIGHTS}

Mechanisms that may underlie cisplatin-induced ototoxicity include excessive ROS, inflammation, cellular uptake of cisplatin, and autophagy, which result in cell death.

Preclinical results have demonstrated numerous interventions that reduce cisplatin-induced ototoxicity. These include small molecular compounds and various drug delivery systems. Potential candidates are nanoparticles and hydrogels that can be delivered via different administration routes and by different dose schedules.

\footnotetext{
Abbreviations: ABR, auditory brainstem response; CCPs, cell-penetrating peptides; DPOAE, distortion product otoacoustic emission; EP, endocochlear potential; HC/SC, hair cell/supporting cell; I.P., intraperitoneal; I.T., intratympanic; MET, mechanoelectrical transducer; NOX3, NADPH oxidase 3; NPs, nanoparticles; RCT, randomized controlled trial; ROS, reactive oxygen species; RWM, round window membrane; SR/ER, sarcoplasmic/endoplasmic reticulum; SV/SL, stria vascularis/spiral ligament.
} 
Although 2 recent phase III clinical trials (Freyer et al., 2017; Brock et al., 2018) have shown reduced incidence and severity of cisplatin-related ototoxicity, further clinical trials are required.

\section{INTRODUCTION}

Cisplatin is a widely used chemotherapeutic agent with a high degree of ototoxicity and an average incidence of over $60 \%$ (Karasawa and Steyger, 2015). Ototoxicity depends on several factors, including patient age, cumulative dose of cisplatin, and genetic susceptibility (Landier, 2016; Lanvers-Kaminsky and Ciarimboli, 2017). The effect of ototoxicity is greatest for children due to potential delays in education and psychosocial development (Knight et al., 2005).

Ototoxicity encompasses the cochlea (cochleotoxicity) and the vestibule (vestibulotoxicity). Cochleotoxicity manifests as hearing loss and tinnitus with substantial impact on communication (Watts, 2019). Hearing loss is bilateral, progressive, and irreversible, with impairment beginning at higher frequencies and extending to lower ones (Rybak, 2007).

The underlying basis for ototoxicity can be multifactorial. Cellular damage may be reflected by changes in functional measurements such as endocochlear potential (EP), auditory brainstem response (ABR), and distortion product otoacoustic emissions (DPOAE) (Gentilin et al., 2019). The underlying mechanistic basis for ototoxicity, which could serve as a starting point for rational drug design, is unknown. Extensive systemic and local therapies to prevent hearing loss have been evaluated. However, none have been approved by the FDA.

This review summarizes the generally accepted underlying basis for cisplatin-induced ototoxicity, explores experimental animal strategies to limit ototoxicity, and introduces limited clinical trials that evaluate approaches to reduce ototoxicity.

\section{MECHANISMS OF CISPLATIN-INDUCED OTOTOXICITY}

he mechanistic basis for ototoxicity induced by cisplatin is not fully understood. However, cisplatin is known to damage the organ of Corti, the spiral ganglion, and the stria vascularis as primary targets. Experimental studies have shown that cellular uptake of cisplatin, oxidative stress, inflammation, apoptosis, and autophagy can play major roles in the pathogenesis of cisplatininduced ototoxicity.

\section{Cisplatin Uptake}

Recent evidence suggests that long-term retention of cisplatin in the inner ear drives cisplatin ototoxicity (Breglio et al., 2017). It has been reported that systemic gentamicin is trafficked via the endolymph into cochlear cells (Wang and Steyger, 2009; Li and Steyger, 2011). If cisplatin acts in a similar manner, two pathways are involved; passive diffusion, and active uptake by a number of membrane-embedded proteins (Hall et al., 2008).
These include mechanoelectrical transducer (MET) channels (Brock et al., 2012), copper transporters (Ctr1, Ctr2), organic cation transporter (OCT2), and transient receptor potential channel (TRPV1), which may contribute to cisplatin influx (Waissbluth and Daniel, 2013). However, there is increasing skepticism regarding protein-mediated cisplatin uptake for the following reasons; (1) the irreversible binding of platinum to CTR1 protein (Ivy and Kaplan, 2013), (2) the unsaturation of platinum uptake via CTR1 (Hall et al., 2008), and (3) the absence of OCT2 in the stria vascularis which denies uptake of cisplatin by vascular networks (Hellberg et al., 2015). Rather, the neutrally charged cisplatin may passively diffuse across the lipid phase of the cell membrane and into the cytoplasm where chloride ligands are replaced through an aquation reaction. The reaction would convert cisplatin to a positively charged diaquo derivative with significantly reduced permeability (Eljack et al., 2014). As described below, the aquated form could then bind to and damage a variety of macromolecules including RNA, proteins, membrane phospholipids, and DNA.

\section{Imbalance of Antioxidant Defense System}

Oxygen is essential to energy generation by a series of one-electron reductions in the mitochondrial electron transport chain. Superoxide radicals $\left(\mathrm{O}_{2}{ }^{-}\right)$, hydrogen peroxide $\left(\mathrm{H}_{2} \mathrm{O}_{2}\right)$, and hydroxyl radicals $\left(\mathrm{OH}^{-}\right)$are generated and known as reactive oxygen species (ROS) (Song et al., 2011). ROS generation may contribute to hearing loss due to cisplatin. NADPH oxidase $(\mathrm{NOX}) 3$, which is at least 50 -fold higher in the inner ear than in any other tissue (e.g., fetal kidney, brain, skull) is strongly induced by cisplatin (Banfi et al., 2004; Karasawa and Steyger, 2015). Knockdown of this gene by siRNA administration to the middle ear ameliorates hearing loss (Mukherjea et al., 2010; Rybak et al., 2012). Another source of ROS in the cochlea is xanthine oxidase (XO) (Lynch et al., 2005). A combination of XO and its substrate hypoxanthine (HX) induce a rise in cytosolic free calcium, resulting in a change in outer hair cell (OHC) motility (Ikeda et al., 1993). Moreover, increased ROS opens $\mathrm{Ca}^{2+}$-permeable channels in sarcoplasmic/endoplasmic reticulum (SR/ER) membranes $\left(\mathrm{IP}_{3} \mathrm{R}\right.$ and $\left.\mathrm{RyR}\right)$ and plasma membranes (TRPV1, L-type, and T-type calcium channels) (Song et al., 2011), leading to an increase in cytosolic calcium levels and eventual apoptotic and autophagic cell death (Pinton et al., 2008).

Enhanced cellular ROS production is balanced by oxygen radical scavengers and antioxidant enzymes that neutralize oxidative damage and include superoxide dismutase (SOD), catalase (CAT), glutathione peroxidase (GSH.Px), and glutathione (GSH) (Sheth et al., 2017). Depletion of antioxidants after exposure to cisplatin has been found in most studies (Lautermann et al., 1997; Rybak et al., 2000; Rybak, 2007), with the exception that SOD activity is significantly increased (Gonzalez-Garcia et al., 2010).

In addition, ROS overload and depletion of antioxidant systems may allow cochlear lipid peroxidation as evidenced by the accumulation of malondialdehyde and toxic lipid peroxides, as well as aldehydes, such as 4-hydroxynonenal and peroxynitrite (Kopke et al., 1999; Lee et al., 2004a; Rybak, 2007). 


\section{Inflammatory Reaction}

Cisplatin increases the early immediate release and de novo synthesis of pro-inflammatory cytokines TNF- $\alpha$, IL- $1 \beta$, and IL- 6 through the activation of ERK and NF-kB. However, antioxidants such as N-acetylcysteine (NAC) and GSH do not affect the secretion of pro-inflammatory cytokines, which suggests that inflammation is an upstream signal of ROS production (So et al., 2007). In another study, ROS generation through NADPH oxidase (NOX)3 triggered an inflammatory process by increasing the expression of COX-2, iNOS, and TNF- $\alpha$ in the cochlea through activation of signal transducer and activator of transcription-1 (STAT1) (Kaur et al., 2011). STAT6 signaling plays a pivotal role in cisplatin-mediated proinflammatory cytokine (IL-4 and IL-13) production and induction of ototoxicity (Kim et al., 2011).

\section{Apoptosis}

ROS excess, lipid peroxidation, calcium influx, and inflammation can induce cellular apoptosis. Moreover, binding of cisplatin to DNA forms inter- and intra-strand cross-linking, which results in cytotoxicity (Casares et al., 2012). This pathological process induces death receptor (Devarajan et al., 2002; Jeong et al., 2007) and mitochondria-mediated (Garcia-Berrocal et al., 2007) apoptotic pathways. The pathways increase pro-apoptotic expression of Bax and decrease Bax-binding protein Bcl-2 family members, which change the permeability of mitochondrial membranes, releasing cytochrome c, activating caspase-9, and downstream caspase-3. The involvement of death receptor-dependent apoptosis is controversial in that caspase 8 is inactivated (Lee et al., 2004b; Garcia-Berrocal et al., 2007).

Further, cisplatin may induce ER stress in cochlear cells by activating caspase12 (an initiator caspase located on the ER membrane) and subsequently triggering apoptosis in a mitochondria-independent manner (Zong et al., 2017).

\section{Autophagy}

Although autophagy is considered to be a contributor to cell survival through degradation of dysfunctional cytoplasmic components, it is also associated with cell death (McPhee et al., 2010). Autophagy differs from caspase-dependent apoptosis in that it is stimulated by oxidative and nitrosative stress (Filomeni et al., 2015). Both activation and inhibition of autophagy can reduce cisplatin-induced ototoxicity. For example, inhibition of ROS generation significantly prevents autophagy activation and apoptosis in response to cisplatin exposure (Yin et al., 2018). Further, enhancing autophagy can alleviate cisplatininduced ototoxicity in rats (Liu et al., 2019) and zebrafish (Pang et al., 2018).

\section{Genetic Susceptibility to Cisplatin-Induced Ototoxicity}

Candidate gene approaches support the impact of patients' individual genotype on susceptibility of cisplatin-induced ototoxicity. These variants of genes are involved in DNA repair (XPC, eIF3a), detoxification of superoxide (SOD2) and transporters in the efflux of cisplatin (SLC31A1). Meanwhile, some genotypes (GSTs, SLC22A2) occur significantly more often among patients without ototoxicity, which show a protection against cisplatin-induced ototoxicity. These observations were made on small cohorts and independent replication is required. Additionally, high-throughput screens have been applied to search genomic biomarkers (TPMT, COMT, ABCC3, ACYP2) for cisplatin-induced hearing loss; however, independent cohorts for validation are necessary (Lanvers-Kaminsky and Ciarimboli, 2017; Drogemoller et al., 2019).

\section{Others}

Nitrative stress could be another important factor in cisplatininduced ototoxicity. Cisplatin treatment induces the nitration and degradation of cochlear protein LMO4 within the Organ of Corti, spiral ganglion, and stria vascularis (Jamesdaniel et al., 2012). Inhibition of nitration enables the transcription of STAT3-related anti-apoptotic genes in cisplatin-treated UB/ OC1 cells (Rosati et al., 2019). Other nitrated proteins in the cochlear sensory epithelium have been discovered by proteomic analysis (Jamesdaniel et al., 2008). Furthermore, the activation of the iNOS pathway and the generation of nitric oxide is believed to facilitate ototoxicity (Watanabe et al., 2002; Li et al., 2006).

Parthanatos, a specific modality of cell death characterized by excessive activation of Poly (ADP-Ribose) Polymerase-1 (PARP1), is considered to be a cisplatin-induced ototoxic mechanism, which functions through PARP1-NAD ${ }^{+}$-SIRT1-NF-kB activation or a DNA damage-hearing loss pathway (Kim et al., 2016; Tropitzsch et al., 2019). Another programmed cell death pathway, necroptosis, has been demonstrated to contribute to cisplatin ototoxicity (Choi et al., 2019; Ruhl et al., 2019).

\section{Animal Models}

Animal models are necessary for the study of cisplatin-induced ototoxicity. In vitro models such as auditory cell lines (HEI-OC1, UB-OC1, and VOT-E36) and explant cultures of the Organ of Corti are major tools for the evaluation of hair cell loss. In addition to zebrafish used for screening and optimizing potent therapeutic agents (Kros and Steyger, 2019), other in vivo animal models, particularly rodents (mice, rats, and guinea pigs), are utilized for histological analysis of auditory structures and physiological function.

\section{Intraperitoneal Injection (Single/Multi-Dose)}

Cisplatin-induced hearing loss is associated not only with dosage, but also with the administration protocol. Whether used in single high dose or multiple low dose, one cycle or multiple cycles, consecutively or separately, different choices have different mortality rates and levels of hearing damage (Hughes et al., 2014; Harrison et al., 2016). The purpose of each is to establish a viable and stable ototoxicity model.

A single injected dose of cisplatin has been commonly used in that it is effective and practical at concentrations ranging from 10 to $30 \mathrm{mg} / \mathrm{kg}$, as shown in Table $\mathbf{1}$. However, this approach is not similar to clinical chemotherapy in which cisplatin is administered as a single intravenous dose every 4 to 6 weeks 
Drugs

Mechanisms

Animal model/cisplatin

Delivery route $\&$ dose

Outcomes

References

dose

co-incubation, Apocynin solution, 125 and prevented hair cell loss at low concentrations

Apocynin antioxidant

Lactate

Mitoquinone (MitoQ)

Paeoniflorin

Levosimendan

Vitamin C

Alpha-lipoic acid (ALA)

Ginkgolide B

Astaxanthin

Flunarizine

R-phenylisopropyladenosine (R-PIA)

Curcumin

Forskolin

Epigallocatechin-3-gallate (EGCG)

Hydrogen (H2)

$\mathrm{N}$-acetylcysteine (NAC)

KR-22332

Pifithrin- $\alpha(P F T-\alpha)$

Allicin $250 \mathrm{mM}$, for $6 \mathrm{~h}$

antioxidant

antioxidant

antioxidant

antioxidant

antioxidant

antioxidant

antioxidant

antioxidant

anti-inflammation

antioxidant, anti-inflammatory

zebrafish, cisplatin $1 \mathrm{mM}$

guinea pigs, cisplatin I.P., 3 $\mathrm{mg} / \mathrm{kg} /$ week $\times 8$ weeks

intratympanic administration, Ringer's solution, $0.5 \mathrm{~h}$ before cisplatin injection

guinea pigs, cisplatin I.P., 10 $\mathrm{mg} / \mathrm{kg}$

mice, cisplatin I.P., $3 \mathrm{mg} / \mathrm{kg} / \quad$ I.P. $30 \mathrm{mg} / \mathrm{kg}$, for $2 \mathrm{~h}$ before daily cisplatin day $x 7$ days injection

rats, cisplatin I.P., $15 \mathrm{mg} / \mathrm{kg} \quad$ I.P., $100 \mathrm{mg} / \mathrm{kg} /$ day $\times 5$ days, starting 2 days before cisplatin injection

rats, cisplatin I.P., 16 mg/kg intratympanic administration, 100 mg/ml, $0.5 \mathrm{~h}$ before cisplatin injection

$\begin{array}{ll}\text { mice, cisplatin I.P., } 20 \mathrm{mg} / \mathrm{kg} & 0.5 \mathrm{~h} \text { before cisplatin injection } \\ \text { I.P., } 100 \mathrm{mg} / \mathrm{kg} \text { of ALA for } 2 \text { days before/ }\end{array}$ after cisplatin injection

rats, cisplatin I.P., $16 \mathrm{mg} / \mathrm{kg} \quad$ I.P., $10 \mathrm{mg} / \mathrm{kg}$, immediately after cisplatin injection

rats, cisplatin I.P., $14 \mathrm{mg} / \mathrm{kg}$ oral administration, $40 \mathrm{mg} / \mathrm{kg}$ daily through orogastric cannula before cisplatin injection mice, cisplatin I.P., 4 mg/kg/ oral administration, $143 \mu \mathrm{g} / \mathrm{kg}, 12 \mathrm{~h}$ before day $x 4$ days and at the same time as cisplatin delivery

rats, cisplatin I. . $11 \mathrm{mg} / \mathrm{kg}$, intratympanic administration, $0.1 \mathrm{mM}$ using an infusion pump solution $(50 \mu \mathrm{l}), 0.5 \mathrm{~h}$ before cisplatin injection

rat, cisplatin I.P., $16 \mathrm{mg} / \mathrm{kg}$

1.P., $200 \mathrm{mg} / \mathrm{kg}, 1 \mathrm{~h}$ before cisplatin administration and once daily for the following 3 days

antioxidant, anti-inflammation

antioxidant, anti-inflammation

mice, cisplatin I.P., $3 \mathrm{mg} / \mathrm{kg}$ day $x$ days I.P., $1 \mathrm{mg} / \mathrm{kg}$, one day ahead and at $2 \mathrm{~h}$ before cisplatin injection

rats, cisplatin I.P., $11 \mathrm{mg} / \mathrm{kg}$ oral administration, $100 \mathrm{mg} / \mathrm{kg} /$ day $\times 4$ days, 1 day before cisplatin injection

antioxidant, anti-inflammation, increase synaptophysin

guinea pigs, cisplatin I.P., 8 $\mathrm{mg} / \mathrm{kg}$

gaseous $\mathrm{H} 2$ inhalation (2\% in air, $60 \mathrm{~min}$ ) immediately after cisplatin injection

rats, cisplatin I.P., $15 \mathrm{mg} / \mathrm{kg}$

I.P., $500 \mathrm{mg} / \mathrm{kg} /$ day $\times 3$ days, $4 \mathrm{~h}$ after cisplatin on the first day

antioxidant, anti-apoptosis

anti-apoptosis

rats, cisplatin I.P., $14 \mathrm{mg} / \mathrm{kg}$

intratympanic administration, $2 \mathrm{mM}, 0.5 \mathrm{~h}$ before cisplatin injection

mice, cisplatin I.P., 16 mg $/ \mathrm{kg} \quad$ I.P., $2.2 \mathrm{mg} / \mathrm{kg}$, 0.5h before cisplatin

injection on day 0 and daily for 5 days; I.T. $2 \mathrm{Mm}(10 \mu \mathrm{l}), 0.5 \mathrm{~h}$ before cisplatin injection on day 0 and daily for 2 days

anti-apoptosis, anti-Parthanatos mice, cisplatin I.P., 3 mg/kg/ I.P., $18.2 \mathrm{mg} / \mathrm{kg}, 1$ day ahead and at $2 \mathrm{~h}$

day $x 7$ days reduced ABR threshold shift (averaged 17.0

$\mathrm{dB})$, partial outer hair cell protection significant

only at $2,000 \mathrm{~Hz}$

reduced $A B R$ threshold shifts $(28-47 \mathrm{~dB})$

ncreased SGN surviva

elevated signal-noise ratio (SNR) values,

reduced cellular degeneration

decreased DPOAE amplitudes at 2.8, 4, 6, and (Celebi et al., 2013)

$8 \mathrm{kHz}$ frequencies

almost completely protected hearing ability (5- (Kim et al., 2018a)

$10 \mathrm{~dB}$ change vs control)

reduced ABR threshold shift (about 20dB) at 16 (Ma et al., 2015)

and $32 \mathrm{kHz}$ and inhibited vestibular dysfunction

higher signal to noise ratios (SNRs) of DPOAE (Kinal et al., 2019)

in high frequencies

attenuated pro-inflammatory cytokine secretion (So et al., 2008)

reduced ABR threshold shifts, especially at the highest frequency.

decreased ABR thresholds by 20-25 dB at 6- (Fetoni et al., 2014)

$32 \mathrm{kHz}$, increased DPOAE amplitude relative to cisplatin alone

reduced $A B R$ threshold shifts by $5-15 \mathrm{~dB}$,

especially at high frequency regions

16 and $32 \mathrm{kHz}$, attenuated loss of $\mathrm{OHCs}$ in the

basal region, protected ribbon synapses and

$\mathrm{Na}+/ \mathrm{K}+$ ATPase $\alpha 1$ in SV/SL

reduced ABR thresholds (-25dB) at 12.5, 20.0, (Fransson et al., 2017) and $30.0 \mathrm{kHz}$, attenuated $\mathrm{OHC}$ loss, protected

IHC synapses

reduced ABR thresholds (-25dB) and increased (Somdas et al., 2018) DPOAE responses at all frequencies

reduced ABR threshold shifts (-30dB) at $8 \mathrm{kHz} \quad$ (Shin et al., 2013)

reduced ABR threshold shifts from $4-32 \mathrm{kHz}$ (Benkafadar et al.

(20-25dB)

2017)

decreased ABR thresholds in most frequencies (Cai et al., 2019)

except $32 \mathrm{kHz}$, increased OHC and SGN

survival, reduced apoptosis in SV 
Minocycline

Dunnione

anti-Parthanatos anti-apoptosis, anti-Parthanatos

educed ABR threshold shift (10-20dB) in $16 \quad$ (Lee et al., 2011)

guinea pigs, cisplatin I.P., $15 \quad$ I.P., 45 mg/kg, $12 \mathrm{~h}$ before cisplatin $\mathrm{mg} / \mathrm{kg}$ administration

mice, cisplatin I.P., $20 \mathrm{mg} / \mathrm{kg}$, oral administration, $20 \mathrm{mg} / \mathrm{kg}, 12 \mathrm{~h}$ before cisplatin injection for the first dose, once day for 4 consecutive days

Pirenzepine

anti-Parthanatos

Dexamethasone maintain ion homeostasis and immune suppression

GMDTC

chelate platinum

Kenpaullone

AT7519 analogue 7 and

AZD5438

Cimetidine

ORC-13661

JWH015

Capsaicin

inhibit CDK2, antioxidant

inhibit CDK2

competitive OCT substrate

blocks MET channe

activate endocannabinoid/CB2R system

cochlear explant cultures, co-incubation, 3-30

cisplatin, $1.75 \mu \mathrm{g} / \mathrm{ml}$

guinea pigs, cisplatin I.P., 8 intratympanic administration, $1 \mathrm{~h}$ before

$\mathrm{mg} / \mathrm{kg}$

cisplatin injection and daily for 5 days

mice, cisplatin I.P., $5 \mathrm{mg} / \mathrm{kg}$ $2 x$ weekly

mice and rats, cisplatin I.P., $\quad$ intratympanic administration, $310 \mu \mathrm{M}, 1$

$30 \mathrm{mg} / \mathrm{kg}$ before cisplatin injection

mice, cisplatin IP, $10 \mathrm{mg} / \mathrm{kg}$ intratympanic administration, 50 before cisplatin injection

mice, cisplatin I.P., $15 \mathrm{mg} / \mathrm{kg} \quad$ I.P., $12.6 \mathrm{mg} / \mathrm{kg}$, immediately before the cisplatin injection

zebrafish and cochlear $\quad$ co-incubation, $\geq 10 \mu \mathrm{M}, 48 \mathrm{~h}$

explant cultures, $5 \mu \mathrm{M}$

intratympanic administration, $2.5 \mathrm{nM}(50 \mathrm{u})$ $0.5 \mathrm{~h}$ before cisplatin injection

activate endocannabinoid/CB2R rats, cisplatin I.P., 12 mg/kg system

Trichostatin A

Tauroursodeoxycholic acid

(TUDCA)

Fenofibrate regulate apoptosis, intracellular calcium homeostasis, neurotransmitter synthesis and release, and synaptic plasticity promote endoplasmic reticulum (ER) proteostasis

maintain functional peroxisomes and mitochondria, antioxidant cochlear explant cultures, cisplatin $150 \mathrm{mM}$

rats, cisplatin I.P., $4.6 \mathrm{mg} / \mathrm{kg}$ day $\times 3$ days (day 13 )

mice, cisplatin I.P., 4 mg/kg/ day $x 4$ days
(Kim et al., 2016)

8,16 , and $32 \mathrm{kHz}$

attenuated loss of sensory hair cells

(Tropitzsch et al.,

reduced ABR threshold (-40dB) in clicks at a (Shafik et al., 2013)

range of $2-4 \mathrm{kHz}$; preserved structure of

HC\&SC, SV\&SL

(Ge et al., 2019)

reduced ABR threshold shifts $(-10 \mathrm{~dB})$ at 16 or (Teitz et al., 2018)

$32 \mathrm{kHz}$

AT7519-reduced ABR threshold shift at 16, 32 (Hazlitt et al., 2018) $\mathrm{kHz}$ (10 dB); AZD5438-reduced ABR threshold shift at $32 \mathrm{kHz}(-14 \mathrm{~dB})$, respectively

reduced $\mathrm{ABR}$ threshold shifts at 16 and $32 \mathrm{kHz}$ (Ciarimboli et al., 2010)

alleviated zebrafish lateral line and mammalian (Kitcher et al., 2019) hair cell death

reduced $A B R$ threshold shifts (5-20dB) at

$8,16,32 \mathrm{kHz}$, maintained the integrity of ribbon synapses and $\mathrm{Na}+/ \mathrm{K}+-\mathrm{ATPases}$ in the $\mathrm{SV}$

reduced ABR threshold shifts (-20dB) at 8, 16 (Bhatta et al., 2019) and $32 \mathrm{kHz}$

\section{reduced $\mathrm{HC}$ and SGN loss}

(Wang et al., 2013)

reduced ABR threshold shitt (18-28 dB) at 8-

(Kim et al., 2018b) $32 \mathrm{kHz}$

reduced ABR threshold shifts (-10dB) at 4-32 (Kim et al., 2018b) $\mathrm{kHz}$ intratympanic administration, $0.1 \mu \mathrm{M}(50 \mu)$ oral administration, 10 or $20 \mathrm{mg} / \mathrm{kg}, 24 \mathrm{~h}$ before cisplatin injection

co-incubation, 200nM, pre incubation for $1 \mathrm{~h}$ and co-incubation with cisplatin for $48 \mathrm{~h}$

I.P., $100 \mathrm{mg} / \mathrm{kg} \times 5$ days (day 0-5)

I.P., $50 \mathrm{mg} / \mathrm{kg}, 12 \mathrm{~h}$ before cisplatin for first dose, immediately after cisplatin treatment

for second dose and repeated for four consecutive days 
with as many as six repetitions. Multi-dose administrations that mimic clinical regimens are essential. Three cycles of cisplatin with 10-day intervals has been established (Roy et al., 2013; Breglio et al., 2017) and optimized (Fernandez et al., 2019)to simulate clinical applications and minimize health risks and mortality, which also provide a better platform for development of novel therapeutic strategies.

Significant ototoxic differences have been found for different rodent species. For example, guinea pigs exhibit an increased sensitivity to cisplatin compared with mice (Poirrier et al., 2010). Among different mouse strains (CBA/CaJ, C57BL/6J, BALB/cJ mouse), the BALB/cJ strain had the greatest threshold shift after cisplatin injection and the lowest mortality (DeBacker et al., 2020). It suggests the need for careful selection of animal species.

\section{Local Exposure}

The large inter-animal variability observed with systemic drug administration can be overcome by direct administration of cisplatin into the cochlea via an osmotic minipump system (Wolters et al., 2003). Although this intracochlear application is not clinically practical, which is the major drawback of this protocol, the animal model is ideally suitable for studies on otoprotective interventions. On the other hand, the delivery site of cisplatin at basal turn can be an interference factor of the intrinsic base-to-apex gradient in hair cell loss (O'Leary et al., 2001). Additionally, the trans-tympanic route lowers morbidity and dose-dependent cochlear or vestibular toxicity (Callejo et al., 2017).

\section{STRATEGIES TO COMBAT CISPLATIN- INDUCED OTOTOXICITY}

In recent decades, preclinical pharmacological strategies have assessed means by which to reduce the ototoxic effects of cisplatin. However, none have been approved by the FDA. These assessments have been based on the underlying mechanisms identified above. The following describes promising small molecule compounds, novel delivery systems, and routes of delivery in a variety of experimental animal models.

\section{Small Molecule Compounds}

Various studies have assessed the potential protective effects of compounds. These include blockade of cisplatin entry into the cochlear fluid or hair cells. Further, antioxidants are among the most extensively studied agents due to the importance of ROS in ototoxicity. However, a concern exists that the chemotherapeutic efficacy of cisplatin may be reduced (Block et al., 2009). Reductions in inflammatory cytokine levels have been another target for drug development by which to protect from cisplatininduced hearing loss. Finally, strategies to reduce apoptosis or other forms of cell death have shown great promise. Table 1 identifies otoprotective candidates evaluated in the last 10 year, as well as operative pathways by which cochlear cell cytotoxicity is induced.

\section{Drug Delivery Routes}

One of the most important choices for a protective intervention is the route of drug delivery. The amount and distribution of drug depends both on the substance applied and on the application protocol. Pharmacological therapy to the inner ear can be divided into two forms: systemic or local administration. Both have pros and cons.

\section{Systemic Administration}

Systemic administration is a practical and less invasive method for delivery by oral, intravenous, intraperitoneal (I.P.), or subcutaneous routes. As shown in Table 1, these methods of administration are preferable and have protective effects against cisplatin-induced ototoxicity. Among these compounds, many have been applied systemically before the injection of cisplatin for a single dose (Paeoniflorin, Levosimendan) or multi doses (Curcumin, Dunnione), while some are used after cisplatin injection (Ginkgolide B, N-acetylcysteine). For lowfrequency hearing loss, associated with the cochlear apex, systemic administration provides for relatively uniform drug distribution along the cochlea. For high-frequency hearing loss local administration is appropriate (Wang et al., 2018b).

However, there are two challenges. The first is to overcome biological barriers that restrict access to the inner ear. These are the blood-perilymph, blood-endolymph, perilymph-endolymph, and middle-inner ear barriers (Zou et al., 2016). The second is off target side effects of systemic administration and the possibility of drug clearance prior to target site access. Unwanted side effects include hematological changes (Freyer et al., 2017) and decreased antitumor efficacy (Lanvers-Kaminsky et al., 2017).

\section{Local Administration}

The alternative to systemic administration is local drug delivery, which mainly includes intratympanic and intracochlear/ intralabyrinthine delivery (Anderson et al., 2019). Advantages of local delivery include passage through the blood-labyrinth barrier, acquisition of higher drug concentration in the cochlea, and avoidance of "first-pass" metabolism (Plontke et al., 2014). Further, the development of 3D computer simulated delivery and sampling procedures have provided a valuable tool to interpret the amount and distribution of drug within the ear (Salt and Plontke, 2018).

\section{Intratympanic (I.T.) Delivery}

Intratympanic injections of therapeutics (Kenpaullone, JWH015, Capsaicin, etc.) are the most commonly-used local delivery and many of which have been proven effective in hearing protection. Drugs are commonly applied to the round window (RW) niche where it contacts both the round window membrane (RWM) and the stapes footplate. If not cleared through the eustachian tube, higher drug concentrations are found in the scala vestibuli rather than the scala tympani. A decreasing basal-apical drug concentration gradient along the cochlea may limit the therapeutic effect of the drug (Plontke et al., 2008). Caution must be exercised in that vestibulotoxicity can develop with prolonged drug retention (Salt et al., 2016) and cochleotoxicity with higher 
dosage (Okuda et al., 2004) and conductive hearing loss. Moreover, multi-cycle intratumor administration may be required, which can damage tissue and bone and is expensive.

The RW is also a site for chronic drug delivery by a combination of micropump and catheter over a long time course, which provides predictable duration of delivery and consistent drug concentration (Sale et al., 2017). Potential adverse local effects are middle ear granulation (Plontke et al., 2006) and inflammation of the RWM. Furthermore, obstruction (pseudomembrane, fibrous, or fat plug) of the RWM (Alzamil and Linthicum, 2000) is another obstacle to local delivery.

\section{Intracochlear/Intralabyrinthine Delivery}

Intracochlear administration has the advantage of passage through physiological barriers. Compared with I.T. delivery, intracochlear drug delivery systems have the advantages of improved dosing control and reduced drug concentration gradients (Pierstorff et al., 2019). Varied approaches have been developed to improve efficacy including the use of sealing materials to reduce leakage while injecting through the RWM (Plontke et al., 2016) and the application of osmotic minipumps to achieve chronic delivery (Wang et al., 2004; Wolters et al., 2004). Gene therapy and cell transplantation by intracochlear delivery hold future promise for treatment (Salt and Plontke, 2018).

\section{An Optimal Delivery Pattern}

To summarize, the most suitable protocol for treating cisplatininduced ototoxicity is intratympanic injection to be delivered $1 \mathrm{~h}$ before each cisplatin injection, due to superior perilymph concentrations within $1 \mathrm{~h}$ of administration (Chandrasekhar et al., 2000; Hargunani et al., 2006). I.T. delivery has no effect on anticancer effect of the cisplatin by eliminating systemic absorption. While the major obstacle is the trama of middle ear and intratympanic pain, which can be relieved by advanced technique of endoscope and analgesia.

\section{Delivery Systems}

Many strategies for both systemic and local delivery to the inner ear have been developed to improve local effectiveness and to reduce systemic side effects. Innovations in drug delivery systems, including nanoparticles, hydrogels, and environmental stimuli systems have been applied to the inner ear.

\section{Nanoparticles}

Nanoparticles (NPs), characterized by a diameter of $<1 \mu \mathrm{m}$, provide many means by which to deliver drugs to the inner ear, including liposomes, polymer nanoparticles, lipid emulsions, nanocapsules, and solid lipid NPs (Mader et al., 2018). After intratympanic administration, drug can reach the cochlea through the RWM by diffusion of the drug-loaded NPs or by diffusion of the free drug released from NPs (Mader et al., 2018). Initially, NPs with sizes $<200 \mathrm{~nm}$ or with high lipid solubility were thought to penetrate the RWM (Bowe and Jacob, 2010). However, particle size, surface chemistry, and cell-penetrating peptides (CPPs) all have impact on cochlear drug delivery in vivo
(Cai et al., 2017). Specifically, NPs with sizes of 150-300nm, positive surface charge and some particular CCPs (low molecular weight protamine, LMWP) provide an enhancement in cochlear entry (Cai et al., 2017).

Various materials have been used for NP construction, including lipids, inorganic materials (such as gold, carbon or iron), proteins, and polymeric systems (Morachis et al., 2012). Each have a different capacity to reduce cisplatin-induced ototoxicity. For example, Martin-Saldana (Martin-Saldana et al., 2016) designed an NP that not only encapsulated a functional drug (methylprednisolone) but also was active in itself as the NP was constructed of a methacrylic derivatives of $\alpha$-tocopherol (vitamin E). Biodegradable and biocompatible solid lipid nanoparticles (SLNs) are able to increase glucocorticoid dose to the inner ear, improving protection (Cervantes et al., 2019). Hydrophobic agents with short half-lives, such as dexamethasone and $\alpha$-tocopheryl succinate, have been incorporated into NPs with adequate concentrations that reach the inner ear (Martin-Saldana et al., 2017). Moreover, modification to NP surfaces can improve desirable attributes. For example, A666 peptide-conjugated NPs specifically target prestin in OHCs with anticipated otoprotective activity (Wang et al., 2018a).

\section{Hydrogel}

Solutions administered intratympanically tend to be absorbed through the eustachian tube and cleared through the middle ear mucosa, which provides limited temporal exposure to the inner ear. This obstacle is overcome by the use of hydrogel. OTO-104 (poloxamer hydrogel containing dexamethasone) provides a sustained-exposure to dexamethasone and alleviates cisplatininduced ototoxicity (Fernandez et al., 2016). A Diltiazem (calcium-channel blocker)-loaded chitosan-glycerophosphate (CGP) hydrogel has been used as a vehicle to provide controlled and sustained delivery to the inner ear (Naples et al., 2020). In addition, hydrogel itself can be cross-linked with functional reagents, such as genipin or STS, with potential therapeutic effect (Videhult Pierre et al., 2019; Yuksel Aslier et al., 2019). For example, silk fibroin and homogenously deacetylated chitosan formulations undergo spontaneous transformation from an aqueous phase to gel and provide rapid transport to the inner ear and prolonged release through the RWM (Chen et al., 2019; Videhult Pierre et al., 2019). In spite of these attractive properties, there is a concern for subsequent conductive hearing loss due to hydrogel attachment to the RWM. A clinical trial has demonstrated I.T. administration of STShyaluronate gel to be feasible and safe with mild adverse effects, although the protection outcomes were not statistically nor clinically significant (Rolland et al., 2019).

\section{Environmental Stimuli Systems}

The major constraint on effective nanoparticle delivery is their poor cellular internalization. Given this, environmental stimuli systems may increase their effective delivery. The stimuli systems can be divided into endogenous (redox, $\mathrm{pH}$, enzyme) and exogenous (light, heat, magnetic field, and ultrasound) types (Morachis et al., 2012). The former ones occur inherently and are beneficial for clinical application. A designed $\mathrm{pH}$-sensitive 
polymeric nanoparticle system, triggered by an acid environment due to increased ROS and inflammation, can release encapsulated dexamethasone and ameliorate hearing loss by intratympanic administration (Martin-Saldana et al., 2018). Endogenous stimuli are favored by systemic administration and only activated for regulated release at specific sites (Movahedi et al., 2015). In a magnetic field, nanoconstructs consisting of superparamagnetic iron oxide nanoparticles (SPIONs) entrapped within glutathione micelles can be used to sequester extracellular cisplatin before it enters a cell (Martin-Saldana et al., 2017). NPs with encapsulated prednisolone can be delivered magnetically to the cochlea with substantial reduction in hearing loss (Ramaswamy et al., 2017). In vitro, a photosensitive substance, 4 -azidosalicylate activated by UV light, has been used to disable prestin in in isolated OHCs, resulting in permanent electromotility inhibition (Fisher et al., 2012). Although optogenetic applications have not been used to treat cisplatin-induced ototoxicity, possibilities have been described (DiGuiseppi and Zuo, 2019).

\section{Others}

Drug delivery carriers are also suitable for use with cisplatin, including NPs, liposomes, micelles (Baba et al., 2012), and nanocapsules (Boulikas, 2009; Vhora et al., 2014). These can selectively and effectively accumulate in solid tumors, enhancing anticancer potential and reducing toxicity.

\section{CLINICAL TRIALS}

Although an extensive number of preclinical studies have explored protective interventions to reduce cisplatin-induced ototoxicity, there are no generally established clinical guidelines. The challenges for translation of preclinical to clinical trials are: (1) differences in morphology and physiology between the human cochlea and that of experimental animals (Laurell, 2019); (2) identification of ototoxic susceptible patients in that international standards among classification systems do not exist (Knight et al., 2017).

Several well-studied laboratory protective approaches have been extended to the clinic. Two randomized controlled trials (RCTs) have verified the otoprotective effect of intratympanic dexamethasone and $\mathrm{N}$-acetylcysteine, which included attenuation of hearing loss and alleviation of $\mathrm{OHC}$ dysfunction (Marshak et al., 2014; Sarafraz et al., 2018). Another antioxidant, amifostine, significantly reduced cisplatin-induced serious hearing loss in patients with average-risk medulloblastoma (Fouladi et al., 2008; Gurney et al., 2014). Some trials have had contradictory results (Yoo et al., 2014; van As et al., 2016) or protective failure, (Fox et al., 2018), attributed to the difference in drug dosage and timing for administration prior to cisplatin treatment, which might decrease the potential maximal protective effect of the same drug. Therefore, a larger scale research, employing various concentrations to be delivered in precise timing, is required.
Notably, sodium thiosulfate is a promising agent. In a recent multicenter, randomized, phase 3 clinical trial (NCT00652132) (Brock et al., 2018), patients with hepatoblastoma who received STS $6 \mathrm{~h}$ after the cisplatin infusion had a $48 \%$ lower incidence of hearing loss than the cisplatin-alone group. And there was no significant difference in 3-year rates of event-free survival $(82 \%$ vs $79 \%$ ) or overall survival ( $98 \%$ vs $92 \%$ ) between the two groups. Similarly, in another clinical trial (NCT00716976) (Freyer et al., 2017), STS treatment reduced the cumulative incidence of cisplatin-induced hearing loss nearly by half (28.6\% vs $56.4 \%$ ), without jeopardizing overall or event-free survival in participants with localized disease. These results suggest a new era with encouraging possibilities in cases of inevitable cisplatin chemotherapy due to its efficacy and safety.

\section{OPPORTUNITIES AND CHALLENGES}

To reduce cisplatin-induced ototoxicity, there are challenges, including (1) an incomplete understanding of the underlying mechanisms of ototoxicity, (2) selection of an optimal strategy (when to use and by which route) among many alternatives, (3) translation to clinical application.

There is a need to identify the pathogenic basis for cisplatininduced ototoxicity. This identification will guide future advances in effective otoprotective agents. Systemic administration of sodium thiosulfate may have a promising future and 'cocktail treatments' (multi-targeted drug combination) may potentially activate multiple molecular pathways. Moreover, identification of pharmacogenomic markers may reduce cisplatin-induced ototoxicity by identifying patients at greatest risk, or who require closer audiologic monitoring, or may benefit from another platinum derivative, or require a reduced drug dosage. In all cases, interference with antitumor efficacy must be considered. Importantly, an internationally approved strategy needs to be implemented for clinical practice.

\section{AUTHOR CONTRIBUTIONS}

JG, YC, and WK wrote the draft. DY, XW, and HW amended the draft.

\section{FUNDING}

This work was supported by the National Natural Science Foundation of China (No. 81970874, No. 81700899), the Shanghai Municipal Science and Technology Commission (No.19ZR1429400), the Shanghai Municipal Education Commission - Two-hundred Talent (No. 20171919), and the Interdisciplinary research of 9th People's Hospital affiliated to Shanghai Jiao Tong university School of Medicine (No. JYJC201810). 


\section{REFERENCES}

Alzamil, K. S., and Linthicum, F. H.Jr. (2000). Extraneous round window membranes and plugs: possible effect on intratympanic therapy. Ann. Otol. Rhinol. Laryngol. 109 (1), 30-32. doi: 10.1177/000348940010900105

Anderson, C. R., Xie, C., Su, M. P., Garcia, M., Blackshaw, H., and Schilder, A. G. M. (2019). Local Delivery of Therapeutics to the Inner Ear: The State of the Science. Front. Cell Neurosci. 13, 418. doi: 10.3389/fncel.2019.00418

Baba, M., Matsumoto, Y., Kashio, A., Cabral, H., Nishiyama, N., Kataoka, K., et al. (2012). Micellization of cisplatin (NC-6004) reduces its ototoxicity in guinea pigs. J. Control Release 157 (1), 112-117. doi: 10.1016/j.jconrel.2011.07.026

Banfi, B., Malgrange, B., Knisz, J., Steger, K., Dubois-Dauphin, M., and Krause, K. H. (2004). NOX3, a superoxide-generating NADPH oxidase of the inner ear. J. Biol. Chem. 279 (44), 46065-46072. doi: 10.1074/jbc.M403046200

Benkafadar, N., Menardo, J., Bourien, J., Nouvian, R., Francois, F., Decaudin, D., et al. (2017). Reversible p53 inhibition prevents cisplatin ototoxicity without blocking chemotherapeutic efficacy. ЕMBO Mol. Med. 9 (1), 7-26. doi: 10.15252/emmm.201606230

Bhatta, P., Dhukhwa, A., Sheehan, K., Al Aameri, R. F. H., Borse, V., Ghosh, S., et al. (2019). Capsaicin Protects Against Cisplatin Ototoxicity by Changing the STAT3/STAT1 Ratio and Activating Cannabinoid (CB2) Receptors in the Cochlea. Sci. Rep. 9 (1), 4131. doi: 10.1038/s41598-019-40425-9

Block, K., Koch, A., Mead, M., Newman, R. A., and Gyllenhaal, C. (2009). Re: Should supplemental antioxidant administration be avoided during chemotherapy and radiation therapy? J. Natl. Cancer Inst. 101 (2), 124-125; author reply 125-126. doi: 10.1093/jnci/djn446

Borse, V., Al Aameri, R. F. H., Sheehan, K., Sheth, S., Kaur, T., Mukherjea, D., et al. (2017). Epigallocatechin-3-gallate, a prototypic chemopreventative agent for protection against cisplatin-based ototoxicity. Cell Death Dis. 8 (7), e2921. doi: $10.1038 /$ cddis. 2017.314

Boulikas, T. (2009). Clinical overview on Lipoplatin: a successful liposomal formulation of cisplatin. Expert Opin. Invest. Drugs 18 (8), 1197-1218. doi: $10.1517 / 13543780903114168$

Bowe, S. N., and Jacob, A. (2010). Round window perfusion dynamics: implications for intracochlear therapy. Curr. Opin. Otolaryngol. Head Neck Surg. 18 (5), 377-385. doi: 10.1097/MOO.0b013e32833d30fo

Breglio, A. M., Rusheen, A. E., Shide, E. D., Fernandez, K. A., Spielbauer, K. K., McLachlin, K. M., et al. (2017). Cisplatin is retained in the cochlea indefinitely following chemotherapy. Nat. Commun. 8 (1), 1654. doi: 10.1038/s41467-01701837-1

Brock, P. R., Knight, K. R., Freyer, D. R., Campbell, K. C., Steyger, P. S., Blakley, B. W., et al. (2012). Platinum-induced ototoxicity in children: a consensus review on mechanisms, predisposition, and protection, including a new International Society of Pediatric Oncology Boston ototoxicity scale. J. Clin. Oncol. 30 (19), 2408-2417. doi: 10.1200/jco.2011.39.1110

Brock, P. R., Maibach, R., Childs, M., Rajput, K., Roebuck, D., Sullivan, M. J., et al. (2018). Sodium Thiosulfate for Protection from Cisplatin-Induced Hearing Loss. N. Engl. J. Med. 378 (25), 2376-2385. doi: 10.1056/NEJMoa1801109

Cai, H., Liang, Z., Huang, W., Wen, L., and Chen, G. (2017). Engineering PLGA nano-based systems through understanding the influence of nanoparticle properties and cell-penetrating peptides for cochlear drug delivery. Int. J. Pharm. 532 (1), 55-65. doi: 10.1016/j.ijpharm.2017.08.084

Cai, J., Wu, X., Li, X., Ma, C., Xu, L., Guo, X., et al. (2019). Allicin Protects against Cisplatin-Induced Stria Vascularis Damage: Possible Relation to Inhibition of Caspase-3 and PARP-1-AIF-Mediated Apoptotic Pathways. ORL J. Otorhinolaryngol. Relat. Spec. 81 (4), 202-214. doi: 10.1159/000500557

Callejo, A., Durochat, A., Bressieux, S., Saleur, A., Chabbert, C., Domenech Juan, I., et al. (2017). Dose-dependent cochlear and vestibular toxicity of transtympanic cisplatin in the rat. Neurotoxicology 60, 1-9. doi: 10.1016/ j.neuro.2017.02.007

Casares, C., Ramirez-Camacho, R., Trinidad, A., Roldan, A., Jorge, E., and GarciaBerrocal, J. R. (2012). Reactive oxygen species in apoptosis induced by cisplatin: review of physiopathological mechanisms in animal models. Eur. Arch. Otorhinolaryngol. 269 (12), 2455-2459. doi: 10.1007/s00405-012-2029-0

Celebi, S., Gurdal, M. M., Ozkul, M. H., Yasar, H., and Balikci, H. H. (2013). The effect of intratympanic vitamin C administration on cisplatin-induced ototoxicity. Eur. Arch. Otorhinolaryngol. 270 (4), 1293-1297. doi: 10.1007/ s00405-012-2140-2
Cervantes, B., Arana, L., Murillo-Cuesta, S., Bruno, M., Alkorta, I., and VarelaNieto, I. (2019). Solid Lipid Nanoparticles Loaded with Glucocorticoids Protect Auditory Cells from Cisplatin-Induced Ototoxicity. J. Clin. Med. 8 (9), 1464. doi: $10.3390 / \mathrm{jcm} 8091464$

Chandrasekhar, S. S., Rubinstein, R. Y., Kwartler, J. A., Gatz, M., Connelly, P. E., Huang, E., et al. (2000). Dexamethasone pharmacokinetics in the inner ear: comparison of route of administration and use of facilitating agents. Otolaryngol. Head Neck Surg. 122 (4), 521-528. doi: 10.1067/mhn.2000.102578

Chen, Y., Gu, J., Liu, J., Tong, L., Shi, F., Wang, X., et al. (2019). Dexamethasoneloaded injectable silk-polyethylene glycol hydrogel alleviates cisplatin-induced ototoxicity. Int. J. Nanomed. 14, 4211-4227. doi: 10.2147/ijn.S195336

Choi, J., Im, G. J., Chang, J., Chae, S. W., Lee, S. H., Kwon, S. Y., et al. (2013). Protective effects of apocynin on cisplatin-induced ototoxicity in an auditory cell line and in zebrafish. J. Appl. Toxicol. 33 (2), 125-133. doi: 10.1002/jat.1729

Choi, M. J., Kang, H., Lee, Y. Y., Choo, O. S., Jang, J. H., Park, S. H., et al. (2019). Cisplatin-Induced Ototoxicity in Rats Is Driven by RIP3-Dependent Necroptosis. Cells 8 (5), 409. doi: 10.3390/cells8050409

Ciarimboli, G., Deuster, D., Knief, A., Sperling, M., Holtkamp, M., Edemir, B., et al. (2010). Organic cation transporter 2 mediates cisplatin-induced oto- and nephrotoxicity and is a target for protective interventions. Am. J. Pathol. 176 (3), 1169-1180. doi: 10.2353/ajpath.2010.090610

DeBacker, J. R., Harrison, R. T., and Bielefeld, E. C. (2020). Cisplatin-induced threshold shift in the $\mathrm{CBA} / \mathrm{CaJ}, \mathrm{C} 57 \mathrm{BL} / 6 \mathrm{~J}, \mathrm{BALB} / \mathrm{cJ}$ mouse models of hearing loss. Hear Res. 387, 107878. doi: 10.1016/j.heares.2019.107878

Devarajan, P., Savoca, M., Castaneda, M. P., Park, M. S., Esteban-Cruciani, N., Kalinec, G., et al. (2002). Cisplatin-induced apoptosis in auditory cells: role of death receptor and mitochondrial pathways. Hear Res. 174 (1-2), 45-54. doi: $10.1016 / \mathrm{s} 0378-5955(02) 00634-2$

DiGuiseppi, J., and Zuo, J. (2019). The awesome power of optogenetics in hearing research. Neurosci. Lett. 701, 175-179. doi: 10.1016/j.neulet.2019.02.037

Drogemoller, B. I., Wright, G. E. B., Lo, C., Le, T., Brooks, B., Bhavsar, A. P., et al. (2019). Pharmacogenomics of Cisplatin-Induced Ototoxicity: Successes, Shortcomings, and Future Avenues of Research. Clin. Pharmacol. Ther. 106 (2), 350-359. doi: 10.1002/cpt.1483

Eljack, N. D., Ma, H. Y., Drucker, J., Shen, C., Hambley, T. W., New, E. J., et al. (2014). Mechanisms of cell uptake and toxicity of the anticancer drug cisplatin. Metallomics 6 (11), 2126-2133. doi: 10.1039/c4mt00238e

Fernandez, R., Harrop-Jones, A., Wang, X., Dellamary, L., LeBel, C., and Piu, F. (2016). The Sustained-Exposure Dexamethasone Formulation OTO-104 Offers Effective Protection against Cisplatin-Induced Hearing Loss. Audiol. Neurootol. 21 (1), 22-29. doi: 10.1159/000441833

Fernandez, K., Wafa, T., Fitzgerald, T. S., and Cunningham, L. L. (2019). An optimized, clinically relevant mouse model of cisplatin-induced ototoxicity. Hear. Res. 375, 66-74. doi: 10.1016/j.heares.2019.02.006

Fetoni, A. R., Eramo, S. L., Paciello, F., Rolesi, R., Podda, M. V., Troiani, D., et al. (2014). Curcuma longa (curcumin) decreases in vivo cisplatin-induced ototoxicity through heme oxygenase-1 induction. Otol. Neurotol. 35 (5), e169-e177. doi: 10.1097/mao.0000000000000302

Filomeni, G., De Zio, D., and Cecconi, F. (2015). Oxidative stress and autophagy: the clash between damage and metabolic needs. Cell Death Differ. 22 (3), 377388. doi: $10.1038 / \mathrm{cdd} .2014 .150$

Fisher, J. A., Nin, F., Reichenbach, T., Uthaiah, R. C., and Hudspeth, A. J. (2012). The spatial pattern of cochlear amplification. Neuron 76 (5), 989-997. doi: 10.1016/j.neuron.2012.09.031

Fouladi, M., Chintagumpala, M., Ashley, D., Kellie, S., Gururangan, S., Hassall, T., et al. (2008). Amifostine protects against cisplatin-induced ototoxicity in children with average-risk medulloblastoma. J. Clin. Oncol. 26 (22), 37493755. doi: 10.1200/jco.2007.14.3974

Fox, E., Levin, K., Zhu, Y., Segers, B., Balamuth, N., Womer, R., et al. (2018). Pantoprazole, an Inhibitor of the Organic Cation Transporter 2, Does Not Ameliorate Cisplatin-Related Ototoxicity or Nephrotoxicity in Children and Adolescents with Newly Diagnosed Osteosarcoma Treated with Methotrexate, Doxorubicin, and Cisplatin. Oncologist 23 (7), 762-e779. doi: 10.1634/ theoncologist.2018-0037

Fransson, A. E., Kisiel, M., Pirttila, K., Pettersson, C., Videhult Pierre, P., and Laurell, G. F. E. (2017). Hydrogen Inhalation Protects against Ototoxicity Induced by Intravenous Cisplatin in the Guinea Pig. Front. Cell Neurosci. 11, 280. doi: $10.3389 /$ fncel.2017.00280 
Freyer, D. R., Chen, L., Krailo, M. D., Knight, K., Villaluna, D., Bliss, B., et al. (2017). Effects of sodium thiosulfate versus observation on development of cisplatin-induced hearing loss in children with cancer (ACCL0431): a multicentre, randomised, controlled, open-label, phase 3 trial. Lancet Oncol. 18 (1), 63-74. doi: 10.1016/s1470-2045(16)30625-8

Garcia-Berrocal, J. R., Nevado, J., Ramirez-Camacho, R., Sanz, R., GonzalezGarcia, J. A., Sanchez-Rodriguez, C., et al. (2007). The anticancer drug cisplatin induces an intrinsic apoptotic pathway inside the inner ear. Br. J. Pharmacol. 152 (7), 1012-1020. doi: 10.1038/sj.bjp.0707405

Ge, Y., Zheng, N., Chen, X., Zhu, J., Sun, W., Olson, J. R., et al. (2019). GMDTC Chelating Agent Attenuates Cisplatin-Induced Systemic Toxicity without Affecting Antitumor Efficacy. Chem. Res. Toxicol. 32 (8), 1572-1582. doi: 10.1021/acs.chemrestox.9b00097

Gentilin, E., Simoni, E., Candito, M., Cazzador, D., and Astolfi, L. (2019). Cisplatin-Induced Ototoxicity: Updates on Molecular Targets. Trends Mol. Med. 25 (12), 1123-1132. doi: 10.1016/j.molmed.2019.08.002

Ghosh, S., Sheth, S., Sheehan, K., Mukherjea, D., Dhukhwa, A., Borse, V., et al. (2018). The Endocannabinoid/Cannabinoid Receptor 2 System Protects Against Cisplatin-Induced Hearing Loss. Front. Cell Neurosci. 12, 271. doi: $10.3389 /$ fncel.2018.00271

Gonzalez-Garcia, J. A., Nevado, J., Garcia-Berrocal, J. R., Sanchez-Rodriguez, C., Trinidad, A., Sanz, R., et al. (2010). Endogenous protection against oxidative stress caused by cisplatin: role of superoxide dismutase. Acta Otolaryngol. 130 (4), 453-457. doi: 10.3109/00016480903311203

Gozeler, M. S., Ekinci Akdemir, F. N., Yildirim, S., Sahin, A., Eser, G., and Askin, S. (2019). Levosimendan ameliorates cisplatin-induced ototoxicity: Rat model. Int. J. Pediatr. Otorhinolaryngol. 122, 70-75. doi: 10.1016/j.ijporl.2019.04.004

Guo, X., Bai, X., Li, L., Li, J., and Wang, H. (2018). Forskolin protects against cisplatin-induced ototoxicity by inhibiting apoptosis and ROS production. BioMed. Pharmacother. 99, 530-536. doi: 10.1016/j.biopha.2018.01.080

Gurney, J. G., Bass, J. K., Onar-Thomas, A., Huang, J., Chintagumpala, M., Bouffet, E., et al. (2014). Evaluation of amifostine for protection against cisplatininduced serious hearing loss in children treated for average-risk or high-risk medulloblastoma. Neuro Oncol. 16 (6), 848-855. doi: 10.1093/neuonc/not241

Hall, M. D., Okabe, M., Shen, D. W., Liang, X. J., and Gottesman, M. M. (2008). The role of cellular accumulation in determining sensitivity to platinum-based chemotherapy. Annu. Rev. Pharmacol. Toxicol. 48, 495-535. doi: 10.1146/ annurev.pharmtox.48.080907.180426

Hargunani, C. A., Kempton, J. B., DeGagne, J. M., and Trune, D. R. (2006). Intratympanic injection of dexamethasone: time course of inner ear distribution and conversion to its active form. Otol. Neurotol. 27 (4), 564569. doi: 10.1097/01.mao.0000194814.07674.4f

Harrison, R. T., Seiler, B. M., and Bielefeld, E. C. (2016). Ototoxicity of $12 \mathrm{mg} / \mathrm{kg}$ cisplatin in the Fischer 344/NHsd rat using multiple dosing strategies. Anticancer Drugs 27 (8), 780-786. doi: 10.1097/cad.0000000000000395

Hazlitt, R. A., Teitz, T., Bonga, J. D., Fang, J., Diao, S., Iconaru, L., et al. (2018). Development of Second-Generation CDK2 Inhibitors for the Prevention of Cisplatin-Induced Hearing Loss. J. Med. Chem. 61 (17), 7700-7709. doi: 10.1021/acs.jmedchem.8b00669

Hellberg, V., Gahm, C., Liu, W., Ehrsson, H., Rask-Andersen, H., and Laurell, G. (2015). Immunohistochemical localization of OCT2 in the cochlea of various species. Laryngoscope 125 (9), E320-E325. doi: 10.1002/lary.25304

Hughes, A. L., Hussain, N., Pafford, R., and Parham, K. (2014). Dexamethasone otoprotection in a multidose cisplatin ototoxicity mouse model. Otolaryngol. Head Neck Surg. 150 (1), 115-120. doi: 10.1177/0194599813511948

Ikeda, K., Sunose, H., and Takasaka, T. (1993). Effects of free radicals on the intracellular calcium concentration in the isolated outer hair cell of the guinea pig cochlea. Acta Otolaryngol. 113 (2), 137-141. doi: 10.3109/00016489309135781

Ivy, K. D., and Kaplan, J. H. (2013). A re-evaluation of the role of hCTR1, the human high-affinity copper transporter, in platinum-drug entry into human cells. Mol. Pharmacol. 83 (6), 1237-1246. doi: 10.1124/mol.113.085068

Jamesdaniel, S., Ding, D., Kermany, M. H., Davidson, B. A., Knight, P., Salvi, R., et al. (2008). Proteomic analysis of the balance between survival and cell death responses in cisplatin-mediated ototoxicity. J. Proteome Res. 7 (8), 3516-3524. doi: $10.1021 /$ pr8002479

Jamesdaniel, S., Coling, D., Hinduja, S., Ding, D., Li, J., Cassidy, L., et al. (2012). Cisplatin-induced ototoxicity is mediated by nitroxidative modification of cochlear proteins characterized by nitration of Lmo4. J. Biol. Chem. 287 (22), 18674-18686. doi: 10.1074/jbc.M111.297960

Jeong, H. J., Kim, S. J., Moon, P. D., Kim, N. H., Kim, J. S., Park, R. K., et al. (2007). Antiapoptotic mechanism of cannabinoid receptor 2 agonist on cisplatininduced apoptosis in the HEI-OC1 auditory cell line. J. Neurosci. Res. 85 (4), 896-905. doi: 10.1002/jnr.21168

Karasawa, T., and Steyger, P. S. (2015). An integrated view of cisplatin-induced nephrotoxicity and ototoxicity. Toxicol. Lett. 237 (3), 219-227. doi: 10.1016/ j.toxlet.2015.06.012

Kaur, T., Mukherjea, D., Sheehan, K., Jajoo, S., Rybak, L. P., and Ramkumar, V. (2011). Short interfering RNA against STAT1 attenuates cisplatin-induced ototoxicity in the rat by suppressing inflammation. Cell Death Dis. 2, e180. doi: $10.1038 /$ cddis. 2011.63

Kaur, T., Borse, V., Sheth, S., Sheehan, K., Ghosh, S., Tupal, S., et al. (2016). Adenosine A1 Receptor Protects Against Cisplatin Ototoxicity by Suppressing the NOX3/STAT1 Inflammatory Pathway in the Cochlea. J. Neurosci. 36 (14), 3962-3977. doi: 10.1523/JNEUROSCI.3111-15.2016

Kim, H. J., Oh, G. S., Lee, J. H., Lyu, A. R., Ji, H. M., Lee, S. H., et al. (2011). Cisplatin ototoxicity involves cytokines and STAT6 signaling network. Cell Res. 21 (6), 944-956. doi: 10.1038/cr.2011.27

Kim, H. J., Pandit, A., Oh, G. S., Shen, A., Lee, S. B., Khadka, D., et al. (2016). Dunnione ameliorates cisplatin ototoxicity through modulation of $\mathrm{NAD}(+)$ metabolism. Hear Res. 333, 235-246. doi: 10.1016/j.heares.2015.08.017

Kim, K. H., Lee, B., Kim, Y. R., Kim, M. A., Ryu, N., Jung, D. J., et al. (2018a). Evaluating protective and therapeutic effects of alpha-lipoic acid on cisplatininduced ototoxicity. Cell Death Dis. 9 (8), 827. doi: 10.1038/s41419-018-0888-Z

Kim, S. J., Park, C., Lee, J. N., and Park, R. (2018b). Protective roles of fenofibrate against cisplatin-induced ototoxicity by the rescue of peroxisomal and mitochondrial dysfunction. Toxicol. Appl. Pharmacol. 353, 43-54. doi: 10.1016/j.taap.2018.06.010

Kinal, M. E., Tatlipinar, A., Uzun, S., Keskin, S., Tekdemir, E., Ozbeyli, D., et al. (2019). Investigation of Astaxanthin Effect on Cisplatin Ototoxicity in Rats by Using Otoacoustic Emission, Total Antioxidant Capacity, and Histopathological Methods. Ear Nose Throat J., 145561319866826. doi: 10.1177/0145561319866826

Kitcher, S. R., Kirkwood, N. K., Camci, E. D., Wu, P., Gibson, R. M., Redila, V. A., et al. (2019). ORC-13661 protects sensory hair cells from aminoglycoside and cisplatin ototoxicity. JCI Insight 4 (15), e126764. doi: 10.1172/jci.insight.126764

Knight, K. R., Kraemer, D. F., and Neuwelt, E. A. (2005). Ototoxicity in children receiving platinum chemotherapy: underestimating a commonly occurring toxicity that may influence academic and social development. J. Clin. Oncol. 23 (34), 8588-8596. doi: 10.1200/jco.2004.00.5355

Knight, K. R., Chen, L., Freyer, D., Aplenc, R., Bancroft, M., Bliss, B., et al. (2017). Group-Wide, Prospective Study of Ototoxicity Assessment in Children Receiving Cisplatin Chemotherapy (ACCL05C1): A Report From the Children's Oncology Group. J. Clin. Oncol. 35 (4), 440-445. doi: 10.1200/ jco.2016.69.2319

Kopke, R., Allen, K. A., Henderson, D., Hoffer, M., Frenz, D., and Van de Water, T. (1999). A radical demise. Toxins and trauma share common pathways in hair cell death. Ann. N. Y. Acad. Sci. 884, 171-191. doi: 10.1111/j.17496632.1999.tb08641.x

Kros, C. J., and Steyger, P. S. (2019). Aminoglycoside- and Cisplatin-Induced Ototoxicity: Mechanisms and Otoprotective Strategies. Cold Spring Harb. Perspect. Med. 9 (11), a033548. doi: 10.1101/cshperspect.a033548

Landier, W. (2016). Ototoxicity and cancer therapy. Cancer 122 (11), 1647-1658. doi: $10.1002 / \mathrm{cncr} .29779$

Lanvers-Kaminsky, C., and Ciarimboli, G. (2017). Pharmacogenetics of druginduced ototoxicity caused by aminoglycosides and cisplatin. Pharmacogenomics 18 (18), 1683-1695. doi: 10.2217/pgs-2017-0125

Lanvers-Kaminsky, C., Zehnhoff-Dinnesen, A. A., Parfitt, R., and Ciarimboli, G. (2017). Drug-induced ototoxicity: Mechanisms, Pharmacogenetics, and protective strategies. Clin. Pharmacol. Ther. 101 (4), 491-500. doi: 10.1002/ cpt.603

Laurell, G. (2019). Pharmacological intervention in the field of ototoxicity. HNO 67 (6), 434-439. doi: 10.1007/s00106-019-0663-1

Lautermann, J., Crann, S. A., McLaren, J., and Schacht, J. (1997). Glutathionedependent antioxidant systems in the mammalian inner ear: effects of aging, 
ototoxic drugs and noise. Hear Res. 114 (1-2), 75-82. doi: 10.1016/s0378-5955 (97)00154-8

Lee, J. E., Nakagawa, T., Kim, T. S., Endo, T., Shiga, A., Iguchi, F., et al. (2004a). Role of reactive radicals in degeneration of the auditory system of mice following cisplatin treatment. Acta Otolaryngol. 124 (10), 1131-1135. doi: $10.1080 / 00016480410017521$

Lee, J. E., Nakagawa, T., Kita, T., Kim, T. S., Iguchi, F., Endo, T., et al. (2004b). Mechanisms of apoptosis induced by cisplatin in marginal cells in mouse stria vascularis. ORL J. Otorhinolaryngol. Relat. Spec. 66 (3), 111-118. doi: 10.1159/ 000079329

Lee, C. K., Shin, J. I., and Cho, Y. S. (2011). Protective Effect of Minocycline Against Cisplatin-induced Ototoxicity. Clin. Exp. Otorhinolaryngol. 4 (2), 7782. doi: $10.3342 / \mathrm{ceo} .2011 .4 .2 .77$

Li, H., and Steyger, P. S. (2011). Systemic aminoglycosides are trafficked via endolymph into cochlear hair cells. Sci. Rep. 1, 159. doi: 10.1038/srep00159

Li, G., Liu, W., and Frenz, D. (2006). Cisplatin ototoxicity to the rat inner ear: a role for HMG1 and iNOS. Neurotoxicology 27 (1), 22-30. doi: 10.1016/ j.neuro.2005.05.010

Liu, T., Zong, S., Luo, P., Qu, Y., Wen, Y., Du, P., et al. (2019). Enhancing autophagy by down-regulating GSK-3beta alleviates cisplatin-induced ototoxicity in vivo and in vitro. Toxicol. Lett. 313, 11-18. doi: 10.1016/ j.toxlet.2019.05.025

Lynch, E. D., Gu, R., Pierce, C., and Kil, J. (2005). Reduction of acute cisplatin ototoxicity and nephrotoxicity in rats by oral administration of allopurinol and ebselen. Hear Res. 201 (1-2), 81-89. doi: 10.1016/j.heares.2004.08.002

Ma, W., Hu, J., Cheng, Y., Wang, J., Zhang, X., and Xu, M. (2015). Ginkgolide B protects against cisplatin-induced ototoxicity: enhancement of Akt-Nrf2-HO-1 signaling and reduction of NADPH oxidase. Cancer Chemother. Pharmacol. 75 (5), 949-959. doi: 10.1007/s00280-015-2716-9

Mader, K., Lehner, E., Liebau, A., and Plontke, S. K. (2018). Controlled drug release to the inner ear: Concepts, materials, mechanisms, and performance. Hear Res. 368, 49-66. doi: 10.1016/j.heares.2018.03.006

Marshak, T., Steiner, M., Kaminer, M., Levy, L., and Shupak, A. (2014). Prevention of Cisplatin-Induced Hearing Loss by Intratympanic Dexamethasone: A Randomized Controlled Study. Otolaryngol. Head Neck Surg. 150 (6), 983990. doi: $10.1177 / 0194599814524894$

Martin-Saldana, S., Palao-Suay, R., Trinidad, A., Aguilar, M. R., RamirezCamacho, R., and San Roman, J. (2016). Otoprotective properties of 6alphamethylprednisolone-loaded nanoparticles against cisplatin: In vitro and in vivo correlation. Nanomedicine 12 (4), 965-976. doi: 10.1016/j.nano.2015.12.367

Martin-Saldana, S., Palao-Suay, R., Aguilar, M. R., Ramirez-Camacho, R., and San Roman, J. (2017). Polymeric nanoparticles loaded with dexamethasone or alpha-tocopheryl succinate to prevent cisplatin-induced ototoxicity. Acta Biomater. 53, 199-210. doi: 10.1016/j.actbio.2017.02.019

Martin-Saldana, S., Palao-Suay, R., Aguilar, M. R., Garcia-Fernandez, L., Arevalo, H., Trinidad, A., et al. (2018). pH-sensitive polymeric nanoparticles with antioxidant and anti-inflammatory properties against cisplatin-induced hearing loss. J. Control Release 270, 53-64. doi: 10.1016/j.jconrel.2017.11.032

McPhee, C. K., Logan, M. A., Freeman, M. R., and Baehrecke, E. H. (2010). Activation of autophagy during cell death requires the engulfment receptor Draper. Nature 465 (7301), 1093-1096. doi: 10.1038/nature09127

Morachis, J. M., Mahmoud, E. A., and Almutairi, A. (2012). Physical and chemical strategies for therapeutic delivery by using polymeric nanoparticles. Pharmacol. Rev. 64 (3), 505-519. doi: 10.1124/pr.111.005363

Movahedi, F., Hu, R. G., Becker, D. L., and Xu, C. (2015). Stimuli-responsive liposomes for the delivery of nucleic acid therapeutics. Nanomedicine 11 (6), 1575-1584. doi: 10.1016/j.nano.2015.03.006

Mukherjea, D., Jajoo, S., Kaur, T., Sheehan, K. E., Ramkumar, V., and Rybak, L. P. (2010). Transtympanic administration of short interfering (si)RNA for the NOX3 isoform of NADPH oxidase protects against cisplatin-induced hearing loss in the rat. Antioxid. Redox Signal 13 (5), 589-598. doi: 10.1089/ ars.2010.3110

Nader, M. E., Theoret, Y., and Saliba, I. (2010). The role of intratympanic lactate injection in the prevention of cisplatin-induced ototoxicity. Laryngoscope 120 (6), 1208-1213. doi: 10.1002/lary.20892

Naples, J. G., Ruckenstein, M. J., Singh, J., Cox, B. C., and Li, D. (2020). Intratympanic Diltiazem-Chitosan Hydrogel as an Otoprotectant Against
Cisplatin-Induced Ototoxicity in a Mouse Model. Otol. Neurotol. 41 (1), 115-122. doi: 10.1097/mao.0000000000002417

O'Leary, S. J., Klis, S. F., de Groot, J. C., Hamers, F. P., and Smoorenburg, G. F. (2001). Perilymphatic application of cisplatin over several days in albino guinea pigs: dose-dependency of electrophysiological and morphological effects. Hear. Res. 154 (1-2), 135-145. doi: 10.1016/S0378-5955(01)00232-5

Okuda, T., Sugahara, K., Shimogori, H., and Yamashita, H. (2004). Inner ear changes with intracochlear gentamicin administration in Guinea pigs. Laryngoscope 114 (4), 694-697. doi: 10.1097/00005537-200404000-00018

Pang, J., Xiong, H., Zhan, T., Cheng, G., Jia, H., Ye, Y., et al. (2018). Sirtuin 1 and Autophagy Attenuate Cisplatin-Induced Hair Cell Death in the Mouse Cochlea and Zebrafish Lateral Line. Front. Cell Neurosci. 12, 515. doi: 10.3389/ fncel.2018.00515

Pierstorff, E., Yang, W. W., Chen, Y. A., Cheung, S., Kalinec, F., and Slattery, W. H. (2019). Prevention of cisplatin-induced hearing loss by extended release fluticasone propionate intracochlear implants. Int. J. Pediatr. Otorhinolaryngol. 121, 157-163. doi: 10.1016/j.ijporl.2019.03.021

Pinton, P., Giorgi, C., Siviero, R., Zecchini, E., and Rizzuto, R. (2008). Calcium and apoptosis: ER-mitochondria $\mathrm{Ca} 2+$ transfer in the control of apoptosis. Oncogene 27 (50), 6407-6418. doi: 10.1038/onc.2008.308

Plontke, S. K., Zimmermann, R., Zenner, H. P., and Lowenheim, H. (2006). Technical note on microcatheter implantation for local inner ear drug delivery: surgical technique and safety aspects. Otol. Neurotol. 27 (7), 912-917. doi: 10.1097/01.mao.0000235310.72442.4e

Plontke, S. K., Biegner, T., Kammerer, B., Delabar, U., and Salt, A. N. (2008). Dexamethasone concentration gradients along scala tympani after application to the round window membrane. Otol. Neurotol. 29 (3), 401-406. doi: 10.1097/ MAO.0b013e318161aaae

Plontke, S. K., Glien, A., Rahne, T., Mader, K., and Salt, A. N. (2014). Controlled release dexamethasone implants in the round window niche for salvage treatment of idiopathic sudden sensorineural hearing loss. Otol. Neurotol. 35 (7), 1168-1171. doi: 10.1097/MAO.0000000000000434

Plontke, S. K., Hartsock, J. J., Gill, R. M., and Salt, A. N. (2016). Intracochlear Drug Injections through the Round Window Membrane: Measures to Improve Drug Retention. Audiol. Neurootol. 21 (2), 72-79. doi: 10.1159/000442514

Poirrier, A. L., Van den Ackerveken, P., Kim, T. S., Vandenbosch, R., Nguyen, L., Lefebvre, P. P., et al. (2010). Ototoxic drugs: difference in sensitivity between mice and guinea pigs. Toxicol. Lett. 193 (1), 41-49. doi: 10.1016/ j.toxlet.2009.12.003

Ramaswamy, B., Roy, S., Apolo, A. B., Shapiro, B., and Depireux, D. A. (2017). Magnetic Nanoparticle Mediated Steroid Delivery Mitigates Cisplatin Induced Hearing Loss. Front. Cell Neurosci. 11, 268. doi: 10.3389/fncel.2017.00268

Rolland, V., Meyer, F., Guitton, M. J., Bussieres, R., Philippon, D., Bairati, I., et al. (2019). A randomized controlled trial to test the efficacy of trans-tympanic injections of a sodium thiosulfate gel to prevent cisplatin-induced ototoxicity in patients with head and neck cancer. J. Otolaryngol. Head Neck Surg. 48 (1), 4. doi: 10.1186/s40463-019-0327-x

Rosati, R., Shahab, M., Neumann, W. L., and Jamesdaniel, S. (2019). Inhibition of protein nitration prevents cisplatin-induced inactivation of STAT3 and promotes anti-apoptotic signaling in organ of Corti cells. Exp. Cell Res. 381 (1), 105-111. doi: 10.1016/j.yexcr.2019.05.008

Roy, S., Ryals, M. M., Van den Bruele, A. B., Fitzgerald, T. S., and Cunningham, L. L. (2013). Sound preconditioning therapy inhibits ototoxic hearing loss in mice. J. Clin. Invest. 123 (11), 4945-4949. doi: 10.1172/jci71353

Ruhl, D., Du, T. T., Wagner, E. L., Choi, J. H., Li, S., Reed, R., et al. (2019). Necroptosis and Apoptosis Contribute to Cisplatin and Aminoglycoside Ototoxicity. J. Neurosci. 39 (15), 2951-2964. doi: 10.1523/jneurosci.1384-18.2019

Rybak, L. P., Husain, K., Morris, C., Whitworth, C., and Somani, S. (2000). Effect of protective agents against cisplatin ototoxicity. Am. J. Otol. 21 (4), 513-520.

Rybak, L. P., Mukherjea, D., Jajoo, S., Kaur, T., and Ramkumar, V. (2012). siRNAmediated knock-down of NOX3: therapy for hearing loss? Cell Mol. Life Sci. 69 (14), 2429-2434. doi: 10.1007/s00018-012-1016-3

Rybak, L. P. (2007). Mechanisms of cisplatin ototoxicity and progress in otoprotection. Curr. Opin. Otolaryngol. Head Neck Surg. 15 (5), 364-369. doi: 10.1097/MOO.0b013e3282eee452

Sale, P. J. P., Uschakov, A., Saief, T., Rowe, D. P., Abbott, C. J., Luu, C. D., et al. (2017). Cannula-based drug delivery to the guinea pig round window causes a 
lasting hearing loss that may be temporarily mitigated by BDNF. Hear Res. 356, 104-115. doi: 10.1016/j.heares.2017.10.004

Salt, A. N., and Plontke, S. K. (2018). Pharmacokinetic principles in the inner ear: Influence of drug properties on intratympanic applications. Hear Res. 368, $28-$ 40. doi: 10.1016/j.heares.2018.03.002

Salt, A. N., Hartsock, J. J., Gill, R. M., King, E., Kraus, F. B., and Plontke, S. K. (2016). Perilymph pharmacokinetics of locally-applied gentamicin in the guinea pig. Hear Res. 342, 101-111. doi: 10.1016/j.heares.2016.10.003

Sarafraz, Z., Ahmadi, A., and Daneshi, A. (2018). Transtympanic Injections of Nacetylcysteine and Dexamethasone for Prevention of Cisplatin-Induced Ototoxicity: Double Blind Randomized Clinical Trial. Int. Tinnitus J. 22 (1), 40-45. doi: 10.5935/0946-5448.20180007

Shafik, A. G., Elkabarity, R. H., Thabet, M. T., Soliman, N. B., and Kalleny, N. K. (2013). Effect of intratympanic dexamethasone administration on cisplatininduced ototoxicity in adult guinea pigs. Auris Nasus Larynx 40 (1), 51-60. doi: 10.1016/j.anl.2012.05.010

Sheth, S., Mukherjea, D., Rybak, L. P., and Ramkumar, V. (2017). Mechanisms of Cisplatin-Induced Ototoxicity and Otoprotection. Front. Cell Neurosci. 11, 338. doi: $10.3389 /$ fncel.2017.00338

Shin, Y. S., Song, S. J., Kang, S. U., Hwang, H. S., Choi, J. W., Lee, B. H., et al. (2013). A novel synthetic compound, 3-amino-3-(4-fluoro-phenyl)-1Hquinoline-2,4-dione, inhibits cisplatin-induced hearing loss by the suppression of reactive oxygen species: in vitro and in vivo study. Neuroscience 232, 1-12. doi: 10.1016/j.neuroscience.2012.12.008

So, H., Kim, H., Lee, J. H., Park, C., Kim, Y., Kim, E., et al. (2007). Cisplatin cytotoxicity of auditory cells requires secretions of proinflammatory cytokines via activation of ERK and NF-kappaB. J. Assoc. Res. Otolaryngol. 8 (3), 338355. doi: 10.1007/s10162-007-0084-9

So, H., Kim, H., Kim, Y., Kim, E., Pae, H. O., Chung, H. T., et al. (2008). Evidence that cisplatin-induced auditory damage is attenuated by downregulation of pro-inflammatory cytokines via Nrf2/HO-1. J. Assoc. Res. Otolaryngol. 9 (3), 290-306. doi: 10.1007/s10162-008-0126-y

Somdas, M. A., Gunturk, I., Balcioglu, E., Avci, D., Yazici, C., and Ozdamar, S. (2018). Protective effect of $\mathrm{N}$-acetylcysteine against cisplatin ototoxicity in rats: a study with hearing tests and scanning electron microscopy. Braz. J. Otorhinolaryngol. 86 (1), 30-37. doi: 10.1016/j.bjorl.2018.08.002

Song, M. Y., Makino, A., and Yuan, J. X. (2011). Role of reactive oxygen species and redox in regulating the function of transient receptor potential channels. Antioxid. Redox Signal 15 (6), 1549-1565. doi: 10.1089/ars.2010.3648

Tate, A. D., Antonelli, P. J., Hannabass, K. R., and Dirain, C. O. (2017). Mitochondria-Targeted Antioxidant Mitoquinone Reduces Cisplatin-Induced Ototoxicity in Guinea Pigs. Otolaryngol. Head Neck Surg. 156 (3), 543-548. doi: 10.1177/0194599816678381

Teitz, T., Fang, J., Goktug, A. N., Bonga, J. D., Diao, S., Hazlitt, R. A., et al. (2018). CDK2 inhibitors as candidate therapeutics for cisplatin- and noise-induced hearing loss. J. Exp. Med. 215 (4), 1187-1203. doi: 10.1084/jem.20172246

Tropitzsch, A., Muller, M., Paquet-Durand, F., Mayer, F., Kopp, H. G., Schrattenholz, A., et al. (2019). Poly (ADP-Ribose) Polymerase-1 (PARP1) Deficiency and Pharmacological Inhibition by Pirenzepine Protects From Cisplatin-Induced Ototoxicity Without Affecting Antitumor Efficacy. Front. Cell Neurosci. 13, 406. doi: 10.3389/fncel.2019.00406

van As, J. W., van den Berg, H., and van Dalen, E. C. (2016). Medical interventions for the prevention of platinum-induced hearing loss in children with cancer. Cochrane Database Syst. Rev. 9, Cd009219. doi: 10.1002/14651858. CD009219.pub4

Vhora, I., Khatri, N., Desai, J., and Thakkar, H. P. (2014). Caprylate-conjugated Cisplatin for the development of novel liposomal formulation. AAPS PharmSciTech. 15 (4), 845-857. doi: 10.1208/s12249-014-0106-y

Videhult Pierre, P., Fransson, A., Kisiel, M. A., Damberg, P., Nikkhou Aski, S., Andersson, M., et al. (2019). Middle Ear Administration of a Particulate Chitosan Gel in an in vivo Model of Cisplatin Ototoxicity. Front. Cell Neurosci. 13, 268. doi: 10.3389/fncel.2019.00268

Waissbluth, S., and Daniel, S. J. (2013). Cisplatin-induced ototoxicity: transporters playing a role in cisplatin toxicity. Hear Res. 299, 37-45. doi: 10.1016/ j.heares.2013.02.002
Wang, Q., and Steyger, P. S. (2009). Trafficking of systemic fluorescent gentamicin into the cochlea and hair cells. J. Assoc. Res. Otolaryngol. 10 (2), 205-219. doi: 10.1007/s10162-009-0160-4

Wang, J., Ladrech, S., Pujol, R., Brabet, P., Van De Water, T. R., and Puel, J. L. (2004). Caspase inhibitors, but not c-Jun NH2-terminal kinase inhibitor treatment, prevent cisplatin-induced hearing loss. Cancer Res. 64 (24), $9217-$ 9224. doi: 10.1158/0008-5472.Can-04-1581

Wang, P., Zhang, P., Huang, J., Li, M., and Chen, X. (2013). Trichostatin A protects against cisplatin-induced ototoxicity by regulating expression of genes related to apoptosis and synaptic function. Neurotoxicology 37, 51-62. doi: 10.1016/j.neuro.2013.03.007

Wang, X., Chen, Y., Tao, Y., Gao, Y., Yu, D., and Wu, H. (2018a). A666-conjugated nanoparticles target prestin of outer hair cells preventing cisplatin-induced hearing loss. Int. J. Nanomed. 13, 7517-7531. doi: 10.2147/ijn.S170130

Wang, Y., Han, L., Diao, T., Jing, Y., Wang, L., Zheng, H., et al. (2018b). A comparison of systemic and local dexamethasone administration: From perilymph/cochlea concentration to cochlear distribution. Hear Res. 370, 110. doi: 10.1016/j.heares.2018.09.002

Watanabe, K., Inai, S., Jinnouchi, K., Bada, S., Hess, A., Michel, O., et al. (2002). Nuclear-factor kappa B (NF-kappa B)-inducible nitric oxide synthase (iNOS/ NOS II) pathway damages the stria vascularis in cisplatin-treated mice. Anticancer Res. 22 (6c), 4081-4085.

Watts, K. L. (2019). Ototoxicity: Visualized in Concept Maps. Semin. Hear 40 (2), 177-187. doi: 10.1055/s-0039-1684046

Wolters, F. L., Klis, S. F., de Groot, J. C., Hamers, F. P., Prieskorn, D. M., Miller, J. M., et al. (2003). Systemic co-treatment with alpha-melanocyte stimulating hormone delays hearing loss caused by local cisplatin administration in guinea pigs. Hear Res. 179 (1-2), 53-61. doi: 10.1016/s0378-5955(03)00080-7

Wolters, F. L., Klis, S. F., Hamers, F. P., de Groot, J. C., and Smoorenburg, G. F. (2004). Perilymphatic application of alpha-melanocyte stimulating hormone ameliorates hearing loss caused by systemic administration of cisplatin. Hear Res. 189 (1-2), 31-40. doi: 10.1016/s0378-5955(03)00396-4

Yin, H., Yang, Q., Cao, Z., Li, H., Yu, Z., Zhang, G., et al. (2018). Activation of NLRX1-mediated autophagy accelerates the ototoxic potential of cisplatin in auditory cells. Toxicol. Appl. Pharmacol. 343, 16-28. doi: 10.1016/ j.taap.2018.02.007

Yoo, J., Hamilton, S. J., Angel, D., Fung, K., Franklin, J., Parnes, L. S., et al. (2014). Cisplatin otoprotection using transtympanic L-N-acetylcysteine: a pilot randomized study in head and neck cancer patients. Laryngoscope 124 (3), E87-E94. doi: 10.1002/lary.24360

Yu, X., Man, R., Li, Y., Yang, Q., Li, H., Yang, H., et al. (2019). Paeoniflorin protects spiral ganglion neurons from cisplatin-induced ototoxicity: Possible relation to PINK1/BAD pathway. J. Cell Mol. Med. 23 (8), 5098-5107. doi: $10.1111 /$ jcmm.14379

Yuksel Aslier, N. G., Tagac, A. A., Durankaya, S. M., Calisir, M., Ersoy, N., Kirkim, G., et al. (2019). Dexamethasone-loaded chitosan-based genipin-cross-linked hydrogel for prevention of cisplatin induced ototoxicity in Guinea pig model. Int. J. Pediatr. Otorhinolaryngol. 122, 60-69. doi: 10.1016/j.ijporl.2019.04.003

Zong, S., Liu, T., Wan, F., Chen, P., Luo, P., and Xiao, H. (2017). Endoplasmic Reticulum Stress Is Involved in Cochlear Cell Apoptosis in a Cisplatin-Induced Ototoxicity Rat Model. Audiol. Neurootol. 22 (3), 160-168. doi: 10.1159/000480346

Zou, J., Pyykko, I., and Hyttinen, J. (2016). Inner ear barriers to nanomedicineaugmented drug delivery and imaging. J. Otol. 11 (4), 165-177. doi: 10.1016/ j.joto.2016.11.002

Conflict of Interest: The authors declare that the research was conducted in the absence of any commercial or financial relationships that could be construed as a potential conflict of interest.

Copyright (c) $2020 \mathrm{Yu}, \mathrm{Gu}$, Chen, Kang, Wang and Wu. This is an open-access article distributed under the terms of the Creative Commons Attribution License (CC BY). The use, distribution or reproduction in other forums is permitted, provided the original author(s) and the copyright owner(s) are credited and that the original publication in this journal is cited, in accordance with accepted academic practice. No use, distribution or reproduction is permitted which does not comply with these terms. 